\title{
Terrestrial laser scanning as a tool for assessing tree growth
}

\author{
Jonathan Sheppard ${ }^{(1)}$, \\ Christopher Morhart ${ }^{(1)}$, \\ Jan Hackenberg ${ }^{(1-2-3)}$, \\ Heinrich Spiecker ${ }^{(1)}$
}

\begin{abstract}
Terrestrial laser scanning (TLS) technology is a powerful tool for assessing tree growth based on time series analysis, as it allows a level of scrutiny not achievable using established destructive techniques. We applied TLS technology to $\mathbf{2 1}$ wild cherry trees grown in a research plot near Breisach (southern Germany) in order to build quantitative structure models (QSMs) for each tree. Scans were carried out over three subsequent years (2012-2014), so that three QSMs per each tree were constructed. Using the above approach, we were able to assess the annual growth of the individual wild cherry trees in terms of diameter and height, stem and branch volume, and the merchantable timber fraction. In addition, the growth of single branches of sample trees was detected and quantified. The availability of QSMs based on TLS-derived data allowed the accurate determination of crown length and width, as well as the volume reduction as the result of the tree pruning applied after the first scan (2012). The aboveground biomass (AGB) was assessed for each tree based on the QSM-derived volume and published wood density values for wild cherry, and then compared with AGB values estimated with standard allometric methods, obtaining a very high correlation $\left(r^{2}{ }^{2 d j}=0.941\right)$. We concluded that the proposed approach is an effective non-destructive technique to accurately assess the increase of tree biomass, and discuss its future application in the forestry sector.
\end{abstract}

Keywords: TLS, Time Series Analysis, Prunus avium L., Wild Cherry, Simpletree, Quantitative Structure Models

so that sequential cylinders can be fol- Newnham et al. 2015, Liang et al. 2016). lowed from root collar to tip. The resulting Recent developments have explored the models are referred to as quantitative detection of merchantable wood volume structure models (QSM). QSMs allow for (Dassot et al. 2012) and residual biomass the analysis of volume distribution within a after the extraction of the merchantable single tree (e.g., see Calders et al. 2015). timber (Fernández-Sarría et al. 2013). InQSMs can also be produced from TLS point deed, TLS provides highly detailed informaclouds obtained from trees under leaf-on tion on many tree parameters with a resoconditions by applying appropriate de-nois- lution that is unfeasible by conventional ing procedures (Belton et al. 2013, Hacken- field methods. For example, Moorthy et al. berg et al. 2015b). However, QSMs using (2011), Bayer et al. (2013) and Metz et al. alternative geometrical methodology have (2013) have evaluated the crown properbeen proposed, e.g., based on ellipses ( $\mathrm{Ai}$ - ties of selected species, the latter applying teanu \& Klein 2014). The use of building this technique for assessing the aboveblocks other than cylinders was investi- ground intra- and inter-specific competigated by Akerblom et al. (2015).

Comprehensive literature reviews concerning the application of TLS in forestry have already been published (Lim et al. 2003, Roberts et al. 2007, Van Leeuwen \& Nieuwenhuis 2010, Van Leeuwen et al. 2011, der is characterised by the spatial information concerning itself and the neighbouring cylinders (including its growth direction), tion and its effects on tree growth. Thies et al. (2004) and Liang et al. (2014) assessed stem taper, while Kretschmer et al. (2013) applied the TLS methodology for the detection of branch scars as an indication of internal wood quality.

Empirical time series analysis of tree growth has been previously carried out for the assessment of biomass in poplar (Populus spp.) plantations (Lodhiyal et al. 1995). Case-study analysis of plot-level biomass changes using temporal repeated scans has also been performed (Liang et al. 2012, Srinivasan et al. 2014). Such approaches rely on statistical modelling of the aboveground biomass using traditional tree parameters such as $\mathrm{DBH}$ and tree height as input variables (Burkhart \& Tomé 2012). To date, the application of TLS methodology to time series analysis has been limited. Time series analysis can be performed by 
Tab. 1 - Laser scanner technical specifications and data acquisition parameters.

\begin{tabular}{lll}
\hline \multirow{2}{*}{ Parameter } & \multicolumn{2}{l}{ Year of scan campaign } \\
\cline { 2 - 3 } & 2012 & 2013 \& 2014 \\
\hline Scanner model & $\mathrm{Z}+\mathrm{F}$ Imager 5006 & $\mathrm{Z}+\mathrm{F}$ Imager 5010 \\
\hline Field of view & $310^{\circ} \times 360^{\circ}$ & $320^{\circ} \times 360^{\circ}$ \\
\hline Beam diameter & $3.0 \mathrm{~mm}(1.0 \mathrm{~m}$ distance $)$ & $\sim 3.5 \mathrm{~mm}(0.1 \mathrm{~m}$ distance $)$ \\
\hline Beam divergence & $0.22 \mathrm{mrad}$ & $<0.3 \mathrm{mrad}$ \\
\hline Range & $79 \mathrm{~m}$ & $187.3 \mathrm{~m}$ \\
\hline Accuracy (horizontal $\times$ vertical) & $0.007^{\circ} \mathrm{rms} \times 0.007^{\circ} \mathrm{rms}$ & $0.007^{\circ} \mathrm{rms} \times 0.007^{\circ} \mathrm{rms}$ \\
\hline Resolution range & $0.1 \mathrm{~mm}$ & $0.1 \mathrm{~mm}$ \\
\hline Resolution (horizontal + vertical) & 10,000 pixel $/ 360^{\circ}$ & 10,000 pixel $/ 360^{\circ}$ \\
\hline
\end{tabular}

scanning the same tree or groups of trees over time. For example, Kaasalainen et al. (2014) have been able to detect branch extension and bole diameter increase of a single tree by carrying out five repeat scans over three subsequent years. Van Laar \& Akça (1997) stated that the age, stem diameter and form, basal area, total and merchantable height and volume are important single-tree characteristics that can be used to infer information about the growth of single trees, and consequently the growth of the wider stand; all of these attributes can be deduced from TLS data point clouds. Stem growth and crown development are intrinsically linked (Assmann 1970). Important parameters such as crown projection area, crown width and crown length can be efficiently quantified using the TLS methodology.

The application of precise measurement of standing volume may allow the quantification of wood products. Veneer production is a major product of the high-quality wild cherry (Prunus avium L.) timber. Production goals for such a product stipulate branch free log lengths free of defects. However, wild cherry do not self-prune well (Pryor 1988) as shaded branches quickly die, often leading to the formation of dead knots which are detrimental to wood quality and can be the starting point of wood decay caused by fungi (Spiecker 1994). Therefore, to obtain high quality butt logs artificial pruning is necessary (Thies et al. 2009), removing branches tive pruning (Springmann et al. 2011). ogy to the forestry sector.

\section{Materials and methods}

before they reach a maximum diameter of $2.5 \mathrm{~cm}$ (Sheppard et al. 2016). The classical pruning treatment provides branch removal up to a defined height, while selective pruning removes only only large diameter branches from the entire length of the potential veneer log, as well as small branches that form steep angles with the stem (Springmann et al. 2011). All remaining branches continue to contribute to tree growth, and they will eventually be pruned in the following years. The average annual diameter increment is significantly lower when intensive conventional pruning is applied (leaving only the top 3 whorls intact) as compared with intensive selec-

Annual scans of the same tree can reveal detailed information which can be used to estimate the growth rate of both tree stem and crown. Moreover, such an approach provides a powerful tool to evaluate the effectiveness of silvicultural management interventions such as pruning or thinning. The aim of this paper is to present an example of the application of TLS technol-

The studied trees were located at a agroforestry research plot close to Breisach, southern Germany ( $48^{\circ} 4^{\prime} 24^{\prime \prime} \mathrm{N}, 7^{\circ} 35^{\prime} 26^{\prime \prime} \mathrm{E}$ - $182 \mathrm{~m}$ a.s.l.). Site conditions, climate and growth of wild cherry in this area are comprehensively described by Morhart et al. (2016). Twenty-one wild cherry trees plant-

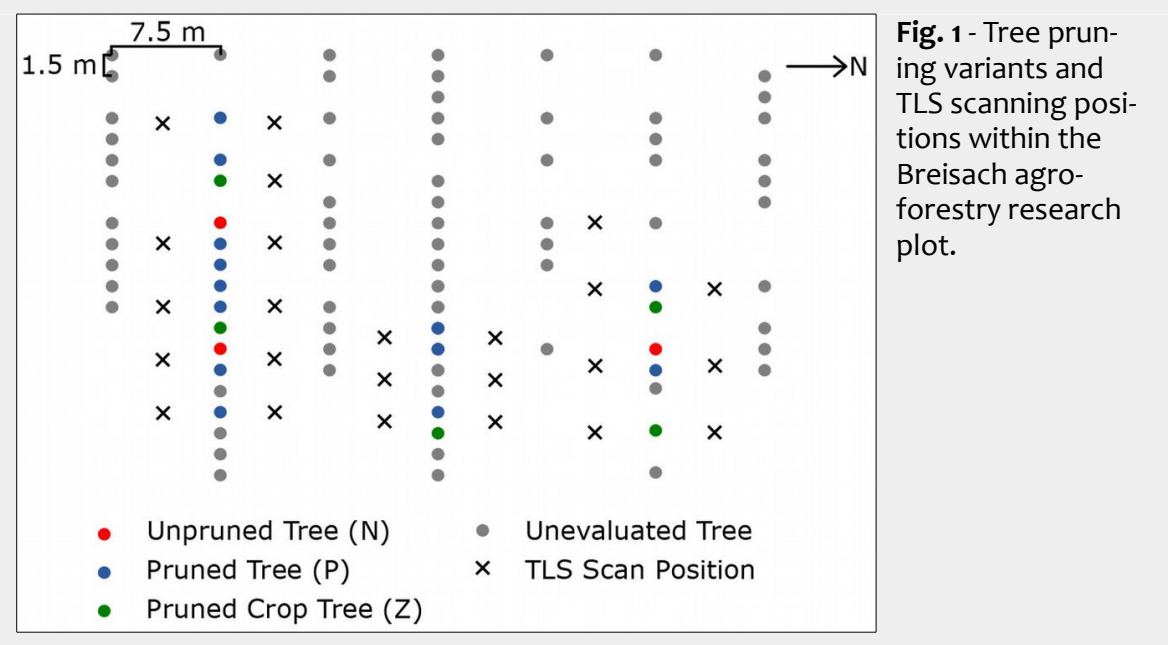

ed in 1997 as two year old saplings have been scanned in late 2012, 2013, and 2014 under leafless conditions. A terrestrial laser scanner (Imager 5006 ${ }^{\circledR}$, Zoller and Frohlich $\mathrm{GmbH}$, Germany) was used for the 2012 scanning campaign and a second scanner (Imager 5010 ${ }^{\circledR}$ ) for the 2013 and 2014 campaigns. Technical specifications and data acquisition parameters are given in Tab. 1. Scan points were marked with durable permanent markers to ensure that the scanner was located in the same position between years. All scans were conducted using the multi-scan mode described by Liang et al. (2016) to provide a high-resolution point cloud data and minimize the occlusion, ensuring between five and seven scan points per tree group. A map of the scanning positions within the study plot is reported in Fig. 1. Scanned areas were targeted with laminated $\mathrm{Z}+\mathrm{F}$ paper targets (Zoller and Frohlich $\mathrm{GmbH}$, Germany). The site was cleared of annual understory vegetation. All the scans were undertaken on days without precipitation and wind to ensure high-quality capture.

Three groups of trees were analysed within the study plot, each group grown under a specific management regime: (i) an unpruned control variant $(\mathrm{N}, \mathrm{n}=3)$ and (ii) a pruned variant $(P, n=13)$, where pruning regimes of differing intensities and techniques were carried out during a single intervention in 2007 (see Springmann et al. 2011 for more details); (iii) a pruned crop tree variant $(Z, n=5)$ encompassing trees pruned in 2007 and 2010, followed by a final pruning treatment to a height of approximately $6 \mathrm{~m}$ during late spring 2013 . The position on the ground of all scanned trees is also reported in Fig. 1.

Point clouds belonging to the same treegroup were co-referenced and placed into a common coordinate system using the software LaserControl ${ }^{\oplus}$ (Zoller and Frohlich $\mathrm{GmbH}$, Germany). Individual trees were cut out of the raw point cloud with the LaserControl software, and then exported in ASCII format. All further processing was performed using the open-source software tool "SimpleTree" (Hackenberg et al. 2015a) based on the method proposed by Hackenberg et al. (2014) which relies on the Point Cloud Library (PCL - Rusu \& Cousins 2011). Ghost points were removed with the statistical outlier removal tool. The trees were isolated by Euclidean clustering and (when needed) by manually including artificial gaps with the crop sphere tool.

The QSMs for the studied trees were built through the following steps. To follow the branching structure of a tree, a sphere centered on the tree skeleton with a radius larger than that of the underlying branch segment was used to extract the sub point cloud on the sphere surface. This sub cloud included the circular structures representing the cross sectional areas of the underlying branch (or branches in the location of branch junctions) into which a circle / num- 
Fig. 2 - Virtual representation (QSM model) of the growth and treatment effects on a pruned crop tree using TLS-derived data over three scan years. Colours represent the diameter class (DC) of the modelled cylinders (red: small DCs; yellow: intermediate DCs; green: large

DCs). Colours and scale are consistent across years. The represented tree was pruned to a height of $6 \mathrm{~m}$ after the first scan (2012).

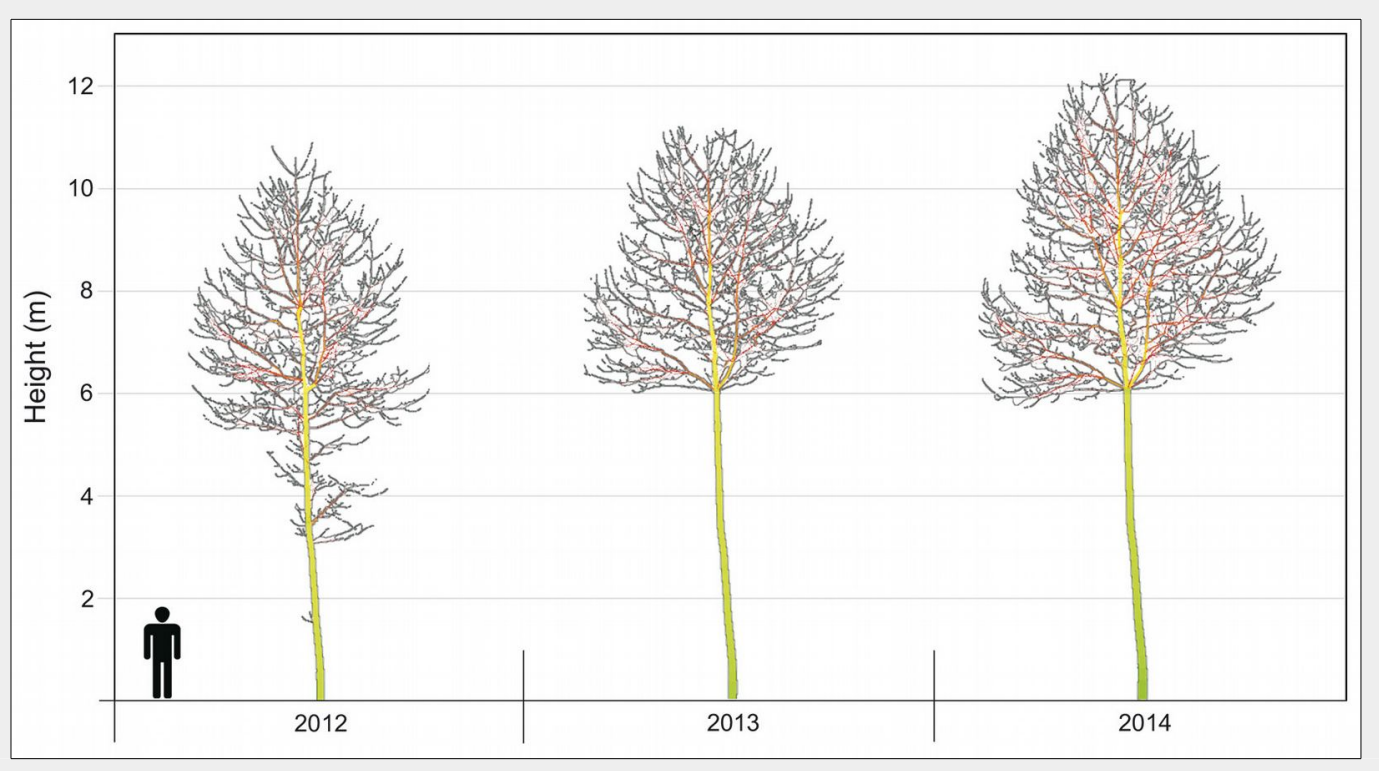

ber of circles were fitted with the random sample consensus (RANSAC) algorithm (Fischler \& Bolles 1981). The sphere center served as a start point of a finite cylinder, the circle center as the end point and the circle radius as the radius of the preliminary detected cylinder. Fitting to the cylinders was improved during the post-processing with a RANSAC implementation. The automatic parameter search proposed in Hackenberg et al. (2015b) was used to ensure complete models and an allometric correction procedure to prevent overestimated twig cylinders (Hackenberg et al. 2015a, 2015b).

Cylinder radius outputs were grouped in diameter classes (DC) during data analysis, so that $D C 1$ included diameters in the range $0-1 \mathrm{~cm}, \mathrm{DC} 2$ included $1-2 \mathrm{~cm}$ diameters, and so forth. Branch angles were calculated by the conversion of Cartesian coordinates $[x$, $y, z]$ to a spherical coordinate system $[\rho, \theta$, $\varphi]$, where $\rho$ is the distance of a point from the origin (here the branch origin on the stem), $\theta$ is the azimuthal angle and $\varphi$ is the zenith angle (hereafter branch angle), which was obtained as follows (eqn. 1):

$$
\phi=\tan ^{-1} \frac{\sqrt{x^{2}+y^{2}}}{z}
$$

Branch angles were determined from the coordinates of the cylinders located within the first $50 \mathrm{~cm}$ of the main ( $1^{\text {st }}$ order) branch, since branch tips could not be used as reference points due to an observed downward movement over time.

The aboveground woody biomass (AGB) of trees was estimated based on the volume derived from TLS data and the homogenised wood density value for wild cherry $\left(0.474 \mathrm{~g} \mathrm{~cm}^{-3}\right)$ proposed by Chave et al. (2009) and Zanne et al. (2009). Such estimates were compared with those obtained using the allometric function set up for the same site and species by Morhart et al. (2016 - eqn. 2):

$$
A G B=0.109 \cdot\left(d_{1.3}\right)^{2.45}
$$

\section{Results and discussion}

TLS methodology for time series analysis allows a greater level of scrutiny compared to manual forest mensuration. The accuracy of the method applied here has been previously proven by comparing destructive field measurements with those obtained by a simple tree algorithm model (Hackenberg et al. 2014, 2015a, 2015b). In this work, we applied a multi-scan methodology to individual trees; however, its extension to assess growth at the stand level is straightforward.

Fig. 2 shows the cylinder models (QSMs) obtained by laser-scanning a sample crop tree $(Z)$ at the plot site in the three consecutive years. The tree was pruned in late spring between the first and second scan, as it can be noticed from the absence of pruned branches in the following years. The increase in tree height and the development of the crown was evident across the three study years.

The basic tree parameters for each tree and year could be extracted based on the obtained cylinder model. The main structural parameters, such as the diameter at breast height $\left(d_{1.3}\right)$, height $(h)$ and crown width $(\mathrm{cw})$, obtained for each pruning vari-

Tab. 2 - Diameter at breast height $\left(\mathrm{d}_{1.3}\right)$, height $(\mathrm{h})$ and crown width $(\mathrm{cw})$ of wild cherry trees in the years 2012-2014 obtained using TLS-derived data. Values are means \pm standard deviation. $(\mathrm{N})$ : unpruned trees; $(\mathrm{P})$ pruned trees; $(\mathrm{Z})$ : pruned crop trees. ${ }^{*}$ ): trees pruned to a height of ca. $6 \mathrm{~m}$ in June 2013.

\begin{tabular}{llrrrr}
\hline \multirow{2}{*}{ Parameter } & $\begin{array}{l}\text { Pruning } \\
\text { Variant }\end{array}$ & $\mathbf{n}$ & \multicolumn{2}{c}{2012} & \multicolumn{2}{c}{2013} & \multicolumn{2}{c}{2014} \\
\hline $\mathrm{d}_{1.3}(\mathrm{~cm})$ & $\mathrm{N}$ & 3 & $10.88 \pm 1.66$ & $11.80 \pm 1.97$ & $12.92 \pm 2.41$ \\
& $\mathrm{P}$ & 13 & $10.31 \pm 2.72$ & $10.94 \pm 2.88$ & $11.80 \pm 3.11$ \\
& $\mathrm{Z}^{*}$ & 5 & $12.64 \pm 1.91$ & $13.48 \pm 1.87$ & $14.54 \pm 2.15$ \\
$\mathrm{~h}(\mathrm{~m})$ & $\mathrm{N}$ & 3 & $8.48 \pm 0.70$ & $9.22 \pm 0.76$ & $9.87 \pm 0.95$ \\
& $\mathrm{P}$ & 13 & $9.02 \pm 1.43$ & $9.74 \pm 1.54$ & $10.23 \pm 1.55$ \\
& $\mathrm{Z}^{*}$ & 5 & $10.76 \pm 0.88$ & $11.54 \pm 1.05$ & $12.18 \pm 1.00$ \\
$\mathrm{CW}(\mathrm{m})$ & $\mathrm{N}$ & 3 & $2.03 \pm 0.12$ & $2.31 \pm 0.04$ & $2.47 \pm 0.06$ \\
& $\mathrm{P}$ & 13 & $1.54 \pm 0.29$ & $1.68 \pm 0.35$ & $1.81 \pm 0.33$ \\
& $\mathrm{Z}^{*}$ & 5 & $2.14 \pm 0.19$ & $1.85 \pm 0.18$ & $2.03 \pm 0.22$ \\
\hline
\end{tabular}

ant over the three years are summarised in Tab. 2. The observed decrease in $\mathrm{cw}$ for crop trees (Z) between 2012 and 2013 can be attributed to the application of the classical pruning treatment, as the trees were pruned up to about $6 \mathrm{~m}$ of height in June 2013.

Only young trees were scanned $(<20$ years), therefore, inferences of stem form and volume are not fully indicative of future tree and stem attributes. Nonetheless, the results obtained through the TLS methodology and the application of SimpleTree software can be used to evaluate if corrective cultural interventions are needed. As only young trees were analysed, changes between years were most pronounced. Juvenile growth of wild cherry trees (especially in height) is expected to peak between 7 and 15 years of age (Joyce et al. 1998). Changes in mature trees across growing seasons may be harder to be detected, and the data files to be processed for mature trees are expected to be much larger than for juvenile trees.

In this study, a stand height curve was produced, based on TLS derived data. The grey lines in Fig. 3 depict the relationship between height and diameter of individual 


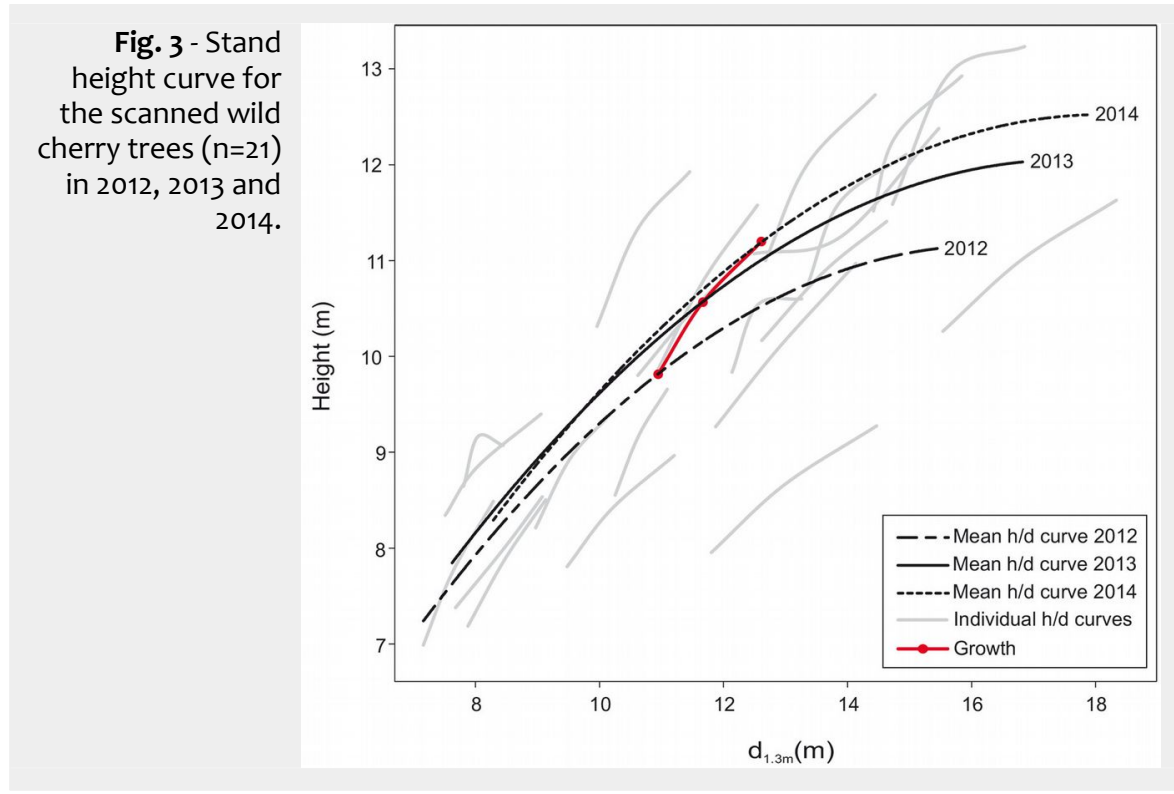

trees $(n=21)$ over the three studied years, while the black trend lines represent the mean development of the stand in the three years. The observed H/D relationships had the typical characteristics of an even-aged single-species stand. Differences in dominance class between individual trees could be clearly observed, shifting as time advances (Pretzsch 2002).

The red line in Fig. 3 represent the mean tree growth across the scanning years. The arithmetic mean of $\mathrm{d}_{1.3}$ from all trees was 10.9, 11.7 and $12.6 \mathrm{~cm}$ in winter 2012, 2013 and 2014, respectively, corresponding to a mean height of 9.8, 10.6 and $11.2 \mathrm{~m}$ for wild cherry trees at this site. This result can be used as a metric for assessing the mean growth of the stand. However, individual tree growth may be affected by tree hierarchy, as well as by a range of factors including microsite and climatic variables. Furthermore, pruning and other management operations may have largely impacted individual tree growth. In any case, the applied methodology allowed to obtain stand height curves, which are valuable tools for practitioners. It is also worth to stress that growth parameters were obtained for a large number of individuals in a relatively short time.

Crop trees ( $Z$ ) displayed an approximate reduction of $50 \%$ in crown volume as a result of the pruning treatment applied in spring 2013. After one further season, most trees still displayed a reduced crown (by 30-40\% compared to the pre-pruning crown volume). The total, stem (root to tip) and branch volume was compared between an unpruned (Fig. 4a) and a pruned tree (Fig. 4b). A reduction in the total and branch volume was evident for the pruned tree (Fig. 4b) as a direct consequence the pruning applied in late spring 2013. However, in the following year (2014) pruned crop trees did regenerate their crowns to almost prepruning volumes. However, differences in crown growth among crop trees were observed, likely due to differences in individual tree vigor, microsite and/or provenance.

Pruning treatment is often adjusted by the operators according to individual tree vigor and development stage, in order to ensure the best tree growth. For this rea- son, the pruning variant groups considered in this study reflected a continuum of variation rather than fully distinct groups. Indeed, some pruned trees considered in this study showed growth characteristics closer to unpruned trees than to other pruned individuals. However, this did not weaken the main results obtained in this study.

The proposed approach allows for the accurate scrutiny of selected parts of the scanned trees within given thresholds. For example, the merchantable timber volume (i.e., stem or branches with diameter $>7$ cm - Van Laar \& Akça 1997) can be easily estimated and small increases of the tree parts could be observed over the three years of the study. The largest observed increase was $51.7 \mathrm{dm}^{3}$ for the stem of a crop tree, whose crown was reduced by the applied pruning. The fastest growing trees increased their total volume by 100 $\mathrm{dm}^{3}$ during the two examined growing seasons, of which $42-52 \mathrm{dm}^{3}$ was merchantable timber volume. Weaker trees accumulated less volume, but in general the increase in merchantable timber volume was $40-60 \%$ of the total increase in tree volume. The most productive trees showed a 80 $110 \%$ increase in crown volume during the two studied growing seasons. The greatest increase $(113 \%)$ was detected for a smaller individual $\left(d_{1.3}=9.1 \mathrm{~cm}\right.$ in 2014) that was previously pruned (in 2012) with an intense classical whorl-wise approach (C2 - Springmann et al. 2011). Similar high growth rates were quite common at the study site, as a consequence of the low initial stocking density which determined a limited competition among trees.

Above-ground biomass for wild cherry at the same site under the same management was already assessed by Morhart et al. (2016) using a destructive sampling methodology. In that study, the total tree biomass (oven dry weight), the stem and the branch fractions could be predicted based on $d_{1.3}$. Using the same regression variable suggested by Morhart et al. (2016), we estimated that the total annual growth of the scanned trees can reach $13 \mathrm{~kg}$, as predicted

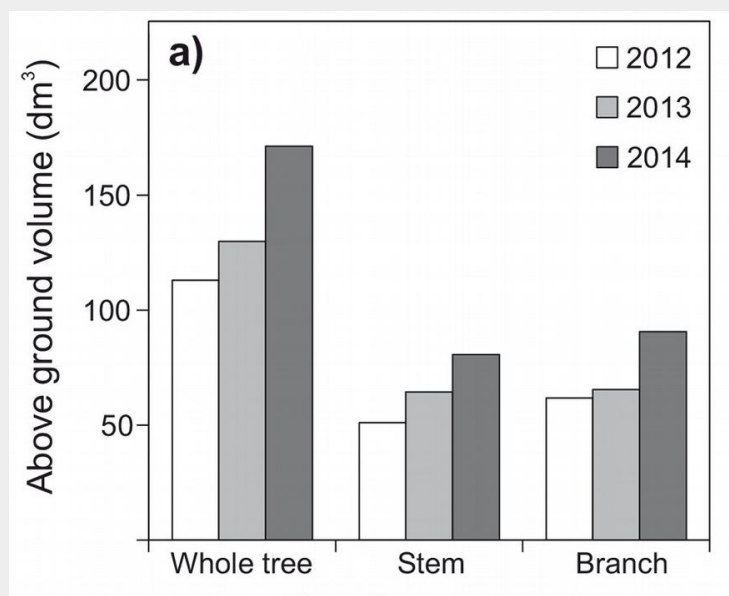

Tree Compartment

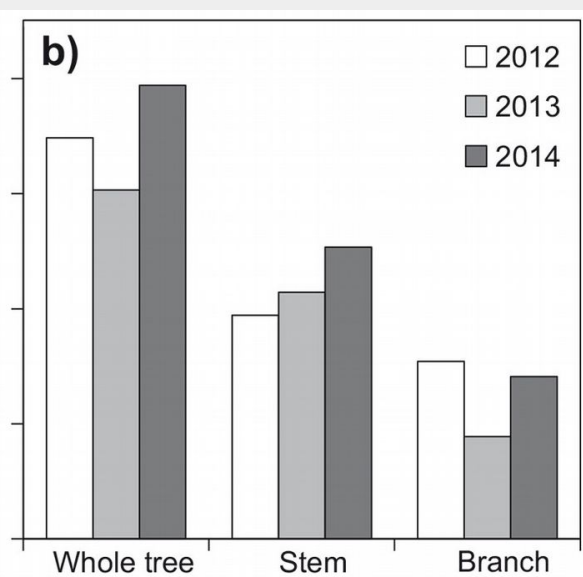

Tree Compartment
Fig. 4 - Total tree volume, stem volume and branch volume by pruning treatment and year for: (a) an unpruned tree; and (b) a crop tree pruned in 2013 after the first scan campaign. 
by the SimpleTree software; this equate to a volume increase of $50 \mathrm{dm}^{3}$ when considering $\mathrm{Z}$ variant trees. Such biomass estimate was obtained based on the volume derived from the TLS data, using the homogenised density value of $0.474 \mathrm{~g} \mathrm{~cm}^{-3}$ for wild cherry given by Chave et al. (2009) and Zanne et al. (2009). However, wood density has been reported to vary both among and within trees (Wassenberg et al. 2015). To verify the consistency of the method used in this study, TLS-derived biomass values were plotted against the total tree aboveground woody biomass values calculated using the allometric function (eqn. 2) proposed by Morhart et al. (2016) for wild cherry at the same site. The results revealed that biomass estimates obtained by the two aforementioned methods are highly correlated $\left(r=0.971 ; r^{2}\right.$ adi $=0.941 ; d f=$ $1.61 ; p<0.001$ - Fig. 5). Based on the above results, we conclude that TLS-derived data provide reliable estimates of total aboveground tree biomass. However, a combination of the two approaches can increase the accuracy of estimations and can be used as a basis for the evaluation of their effectiveness.

As mentioned above, the use of TLS data in biomass estimation provides the opportunity to examine trees with a very high resolution. Contrastingly, the manual calculation of biomass within diameter classes usually requires an extensive and time consuming destructive sampling, which prevent the same individual tree to be further assessed. In this case, a comparable goal could be attained by relying on empirical studies and published allometric biomass equations, as carried out for example by Morhart et al. (2013) for hybrid poplar (Populus spp.) in a short rotation coppice.

Fig. 6 displays the variation in biomass distribution across diameter classes (DC) for a single sampled tree over the three scanning dates. As expected, total biomass increased with time in all the considered DCs, though the largest increase was observed for smaller diameters from the crown (DC1-DC3) and for larger diameters from the lower stem (DC15-DC17), while in the other diameter classes the changes were relatively small. As a general trend, peaks in biomass could be detected in DC3 and DC13-15 (dependent on the tree size) in both pruned and unpruned individuals (not shown).

To assess the growth of single branches based on TLS-derived data, 23 branches from three unpruned trees ( $\mathrm{N}$ variant) were randomly selected and their growth was assessed based on 2012 and 2014 scans. Two branches showing implausible results (negative or exaggerated growth, attributable to either occlusion errors or errors occurring in the cylinder fitting process) were excluded from this analysis. Fig. 7 displays the relationship between the increase in branch volume and the corresponding branch angle $\left(r_{\text {adj }}^{2}=0.386\right.$; $d f$ 1.19; $p=0.002)$. In this case, values of branch
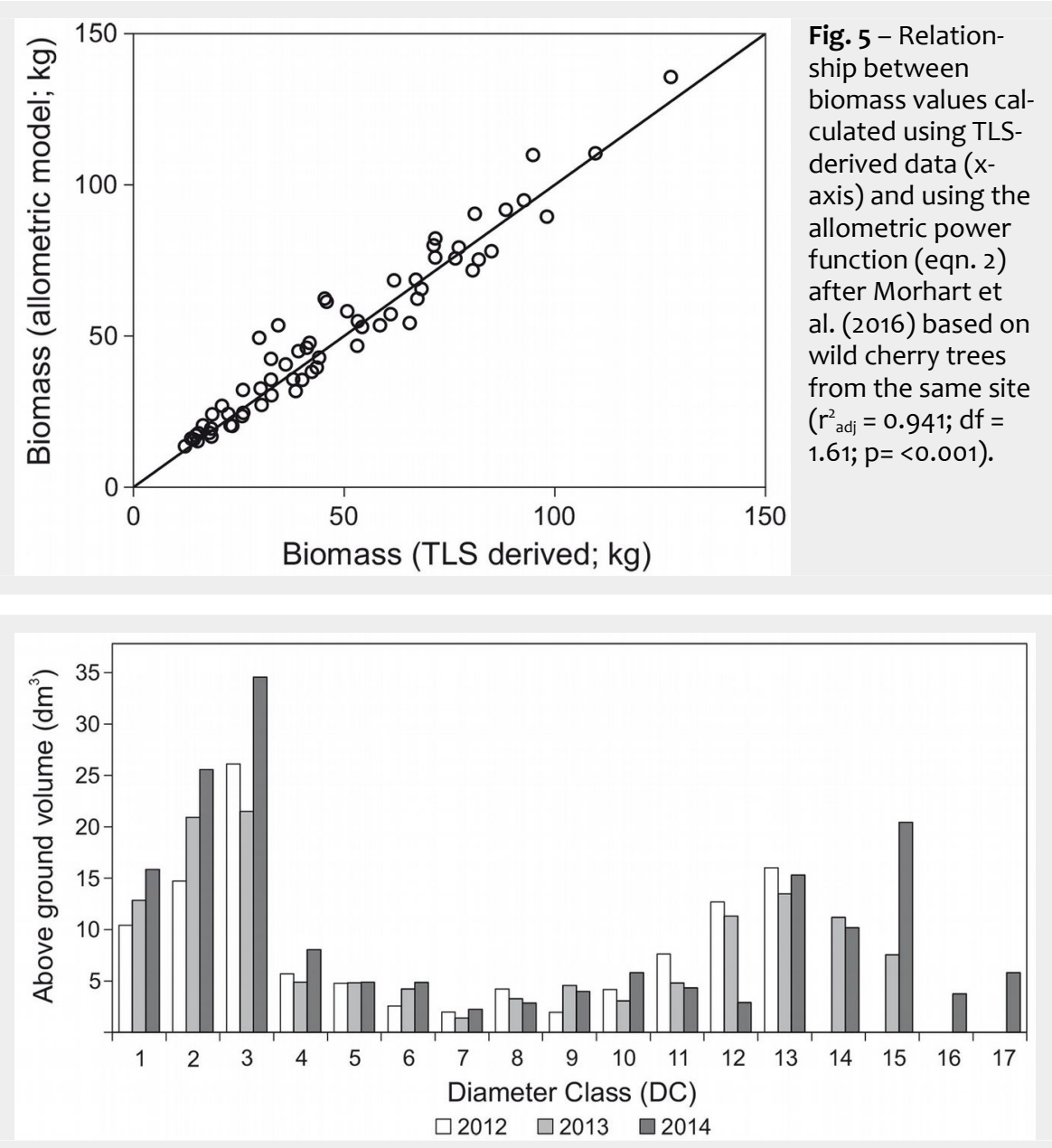

Fig. 6 - Within-tree biomass distribution among different diameter classes (DC1 $=0-1$ $\mathrm{cm}$; $D C 2=1-2 \mathrm{~cm}$; etc.) in the years 2012-2014 for a single unpruned wild cherry tree.

angles (in degrees) were measured from the stem axis below the branch to the central axis of the studied branch after Pretzsch (2002), and steeply angled branches (grey vertical line in Fig. 7) were defined according to Springmann et al. (2011). Despite the low number of samples analysed, the results confirmed that steeply angled branches grow faster (as previously suggested by Schuler 2011), and for this reason they should be removed early in the rota- tion to avoid large knots after pruning. Branch comparison using manual methods is time consuming and prone to error without careful cross-checking. Hence, a reliable automated methodology is required in order to scale up this research based on the TLS data.

As already mentioned, difficulties can arise for the automated identification of individual branches across years using TLSderived data. This can be attributed to their

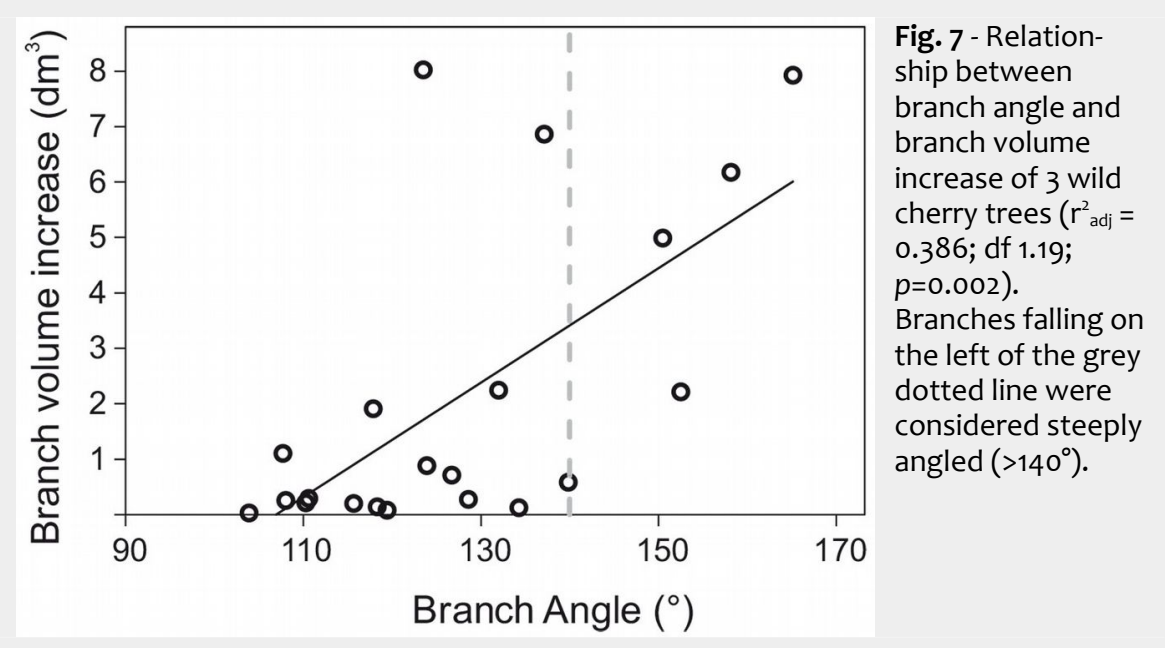




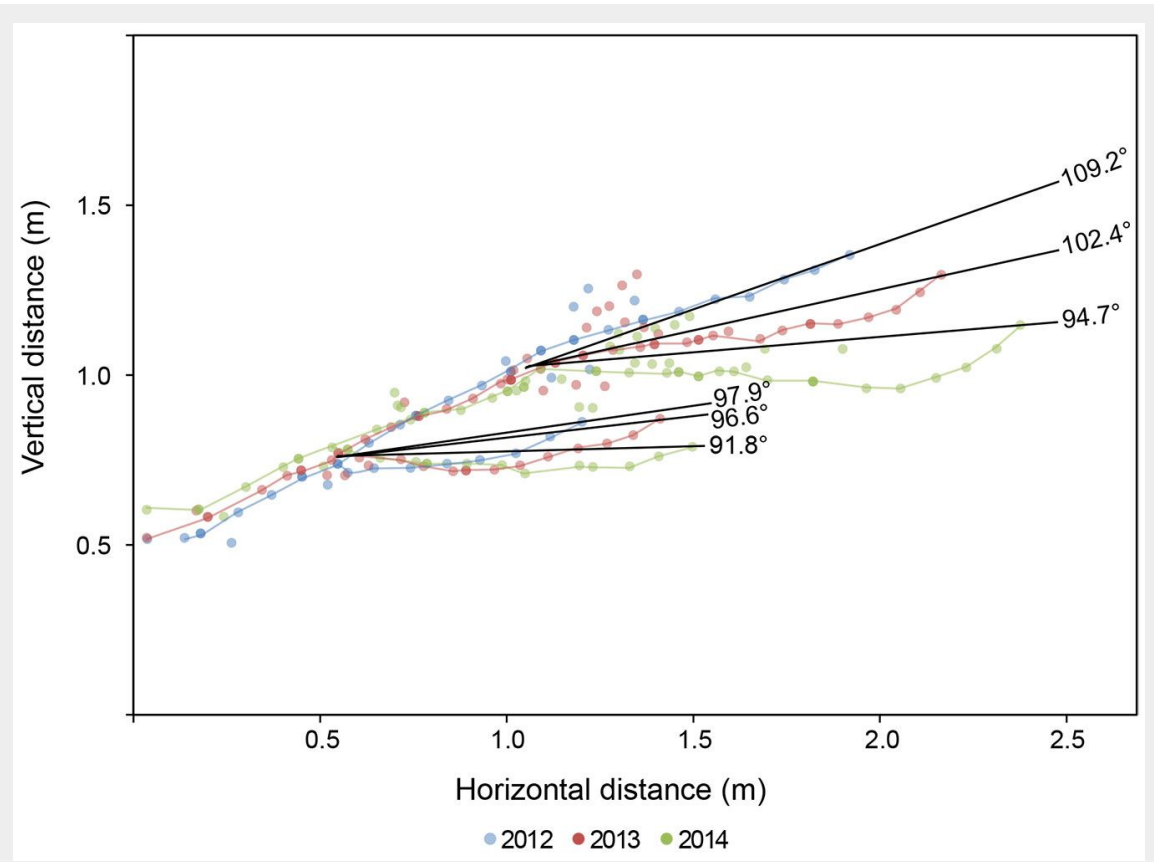

Fig. 8 - Example of downward movements (in degrees from the vertical) of a sample individual branch of a wild cherry tree over time, showing the branch position in the space at different TLS scan years (different colours).

increase in diameter and total length over time, but also to the tendency of branch tips to move downwards as the branch grows, thereby it no longer occupies the same position as identified in previous time series scans. Such occurrence can be measured through time series scans. As an example, Fig. 8 shows the downward movement of a single branch over time based on three consecutive scan points. In this case, the linear branch length and the complementary linear branch angle were defined as in Pretzsch (2002). The upper portion of the sample branch displayed in Fig. 8 has moved downward by $14.5^{\circ}$ from 2012 to 2014, while the smaller branch portion below by $6.1^{\circ}$ at the branch tip over the same period. Indeed, downward movement of the branch tip can be assumed to be a function of branch weight, diameter, length and the angle of origin. The determination of the branch angle by laser scanning is efficient, while the measurement of branch angles represents a challenge using traditional field measurement techniques, in particular when multiple trees over multiple years are considered.

The application of TLS methodology for analysis of tree structural parameters over time is a novel and promising area of research. This research differs from previous investigations insofar that a number of individual trees were scanned as groups, whereas other previous studies have focused on single trees. The algorithm used in this study has shown a high accuracy in the construction of model cylinders. Indeed, the occurrence of incorrect cylinders or their over- or underestimation may cause noise or systematic errors, as previously assessed by Hackenberg et al. (2014, 2015a, 2015b). In this study, the validation of the technique was not carried out and we assumed that modelled cylinders provide a good average fit quality, as confirmed by a visual validation. However, the method can present errors mainly concerning the incorrect attribution of branches or stems, as already reported by Kaasalainen et al. (2014). Occlusion errors remain a shortfall of the current TLS methodology (Kankare et al. 2014) which can be minimised by using multiple scan positions with sufficient targets to ensure that scans are geo-referenced. Nonetheless, the applied automated parameter search method is able to detect configurations which allow spheres to bridge small occlusion gaps (Hackenberg et al. 2015a). We recommend scans to be conducted under suitable weather conditions (i.e., no precipitation and low wind) to maximise the data comparability between can years.

\section{Conclusion}

The objective of this manuscript was to test the use of TLS methodology as a tool for assessing tree growth. Our results demonstrated that such an approach can be successfully applied to detect growth and changes in the structure and form of trees, even over a short time period. The proposed method has proven to be effective in detecting differences among trees in crown length, crown density and bole dimensions, as resulted from the application of many different pruning regimes. Using TLS-derived data, we were able to detect tree volume growth and the reduction in total volume and crown dimensions after pruning, as well as height and diameter growth and changes in crown dimen- sions both within trees and among different pruning regimes. Furthermore, the rate of growth of individual branches and their spatial positioning could be assessed. The application of such an approach to the same tree over time allows a level of investigation not previously attained using established destructive techniques.

Further application of the TLS methodology may include longer temporal measurements on a wider spatial scale, in order to reveal the effect of silvicultural treatments on the growth of remaining trees, and at the same time the potential biomass within harvested individuals. Moreover, the use of TLS-derived data for assessing stem attributes (e.g., sweep, lean, taper, eccentricity and ovality) can provide a straightforward method of tree quality grading, aiding the pre-planning of timber assortments. In conclusion, the methodology proposed here may provide a powerful tool for many applications, such as forest modelling, monitoring and management.

\section{Acknowledgements}

The authors thank Georgios Skiadaresis for data pre-processing and Felix Baab for continued technical support. This research was supported by the EU FP7 project "StarTree" (Grant no. 311919), by the Federal Ministry of Education and Research of germany (BMBF) within the Sino-German Lin2Value project (no. 033L049A), and the German Federal Ministry of Food and Agriculture (BMEL) within the project "AgroWertholz" (support code 22031112).

\section{References}

Aiteanu F, Klein R (2014). Hybrid tree reconstruction from inhomogeneous point clouds. The Visual Computer 30: 763-771. - doi: 10.1007/s003 71-014-0977-7

Akerblom M, Raumonen P, Kaasalainen M, Casella E (2015). Analysis of geometric primitives in quantitative structure models of tree stems. Remote Sensing 7: 4581-4603. - doi: 10.3390/rs 70404581

Aschoff T, Spiecker H (2004). Algorithms for the automatic detection of trees in laser scanner data. In: "International Archives of Photogrammetry". Remote Sensing and Spatial Information Sciences, XXXVI, 8/W2, pp. 71-75. - [online] URL: http://citeseerx.ist.psu.edu/viewdoc/dow nload?doi=10.1.1.222.597\&rep=rep1\&type=pdf Assmann E (1970). The principles of forest yield study. Pergamon Press, Oxford, UK, pp. 506. Bayer D, Seifert S, Pretzsch H (2013). Structural crown properties of Norway spruce (Picea abies [L.] Karst.) and European beech (Fagus sylvatica [L.]) in mixed versus pure stands revealed by terrestrial laser scanning. Trees 27: 1035-1047. - doi: 10.1007/s00468-013-0854-4 Belton D, Moncrieff S, Chapman J (2013). Processing tree point clouds using Gaussian Mixture Models. In: Proceedings of the "ISPRS Workshop Laser Scanning 2013" (Scaioni M, Lindenbergh S, Oude Elberink S, Schneider D, Pirotti F eds). Antalya (Turkey) 11-13 Nov 2013. ISPRS, pp. 43-48. [online] URL: http://www. isprs-ann-photogramm-remote-sens-spatial-inf- 
sci.net/II-5-W2/43/2013/isprsannals-II-5-W2-432013.pdf

Burkhart HE, Tomé M (2012). Modeling forest trees and stands. Springer, Dordrecht, Heidelberg, New York, London, pp. 458. [online] URL: http://books.google.com/books?id=XmcNcfEars oC

Calders K, Newnham G, Burt A, Murphy S, Raumonen P, Herold M, Culvenor DS, Avitabile V, Disney M, Armston J (2015). Nondestructive estimates of above-ground biomass using terrestrial laser scanning. Methods in Ecology and Evolution 6: 198-208. - doi: 10.1111/2041-210X.123 01

Chave J, Coomes DA, Jansen S, Lewis SL, Swenson NG, Zanne AE (2009). Towards a worldwide wood economics spectrum. Ecology Letters 12 (4): 351-366. - doi: 10.1111/j.1461-0248.2009.012 85.x

Dassot M, Colin A, Santenoise P, Fournier M, Constant T (2012). Terrestrial laser scanning for measuring the solid wood volume, including branches, of adult standing trees in the forest environment. Computers and Electronics in Agriculture 89: 86-93. - doi: 10.1016/j.compag.20 12.08.005

Eysn L, Pfeifer N, Ressl C, Hollaus M, Grafl A, Morsdorf F (2013). A practical approach for extracting tree models in forest environments based on equirectangular projections of terrestrial laser scans. Remote Sensing 5: 5424-5448. - doi: 10.3390/rs5115424

Fernández-Sarría A, Velázquez-Martí B, Sajdak M, Martínez L, Estornell J (2013). Residual biomass calculation from individual tree architecture using terrestrial laser scanner and groundlevel measurements. Computers and Electronics in Agriculture 93: 90-97. - doi: 10.1016/j.com pag.2013.01.012

Fischler MA, Bolles RC (1981). Random sample consensus: a paradigm for model fitting with applications to image analysis and automated cartography. Communications of the ACM 24: 381-395. - doi: 10.1145/358669.358692

Gorte B, Winterhalder D (2004). Reconstruction of laser-scanned trees using filter operations in the 3D-raster domain. In: Proceedings of the ISPRS working group VIII/2 "Laser-Scanners for Forest and Landscape Assessment" (Thies M, Koch B, Spiecker H, Weinacker H eds). Freiburg (Germany) 3-6 Oct 2004. ISPRS International Archives, vol. XXXVI-8/W2, pp. 39-44. - [online] URL: http://citeseerx.ist.psu.edu/viewdoc/dow nload?doi=10.1.1.222.769\&rep=rep1\&type $=p d f$

Hackenberg J, Morhart CD, Sheppard JP, Spiecker H, Disney M (2014). Highly accurate tree models derived from terrestrial laser scan data: a method description. Forests 5: 1069-1105. doi: $10.3390 /$ f5051069

Hackenberg J, Spiecker H, Calders K, Disney M, Raumonen P (2015a). SimpleTree - an efficient open source tool to build tree models from TLS clouds. Forests 6: 4245-4294. - doi: 10.3390/f61 14245

Hackenberg J, Wassenberg M, Spiecker H, Sun D (2015b). Non destructive method for biomass prediction combining TLS derived tree volume and wood density. Forests 6: 1274-1300. - doi: $10.3390 / f 6041274$

Jayaratna S (2009). Baumrekonstruktion aus 3DPunktwolken [Tree reconstruction from 3D point clouds]. Diploma Thesis, Institut für Informatik, Rheinische Friedrich-Wilhelms-Universität, Bonn, Germany, pp. 73. [in German]

Joyce PM, Huss J, McCarthy R, Pfeifer A, Hendrick E (1998). Growing broadleaves: silvicultural guidelines for ash, sycamore, wild cherry, beech and oak in Ireland. COFORD, Dublin, pp. 144.

Kaasalainen S, Krooks A, Liski J, Raumonen P, Kaartinen H, Kaasalainen M, Puttonen E, Anttila K, Mäkipää R (2014). Change detection of tree biomass with terrestrial laser scanning and quantitative structure modelling. Remote Sensing 6: 3906-3922. - doi: 10.3390/rs6053906

Kankare V, Joensuu M, Vauhkonen J, Holopainen M, Tanhuanpää T, Vastaranta $M$, Hyyppä J, Hyyppä H, Alho P, Rikala J, Sipi M (2014). Estimation of the timber quality of Scots pine with terrestrial laser scanning. Forests 5: 1879. - doi: 10.3390/f5081879

Kretschmer U, Kirchner N, Morhart CD, Spiecker $H$ (2013). A new approach to assessing tree stem quality characteristics using terrestrial laser scans. Silva Fennica 47 (5): article id 1071. doi: 10.14214/sf.1071

Liang X, Hyyppä J, Kaartinen H, Holopainen M, Melkas T (2012). Detecting changes in forest structure over time with bi-temporal terrestrial laser scanning data. ISPRS International Journal of Geo-Information 1: 242-255. - doi: 10.3390/ ijgi1030242

Liang X, Kankare V, Yu X, Hyyppä J, Holopainen $M$ (2014). Automated stem curve measurement using terrestrial laser scanning. IEEE Transactions on Geoscience and Remote Sensing 52: 1739-1748. - doi: 10.1109/TGRS.2013.2253783

Liang X, Kankare V, Hyyppä J, Wang Y, Kukko A, Haggrén H, Yu X, Kaartinen H, Jaakkola A, Guan F, Holopainen M, Vastaranta M (2016). Terrestrial laser scanning in forest inventories. Theme issue: "State-of-the-art in photogrammetry, remote sensing and spatial information science" 115: 63-77. - doi: 10.1016/j.isprsjprs.2016.01.006 Lim K, Treitz P, Wulder MA, St-Onge B, Flood M (2003). LiDAR remote sensing of forest structure. Progress in Physical Geography 27: 88106. - doi: 10.1191/0309133303pp36ora

Lodhiyal LS, Singh RP, Singh SP (1995). Structure and function of an age series of poplar plantationsin central Himalaya: I. Dry matter dynamics. Annals of Botany 76 (2): 191-199. - doi: 10.1006/anbo.1995.1087

Metz J, Seidel D, Schall P, Scheffer D, Schulze E, Ammer C (2013). Crown modeling by terrestrial laser scanning as an approach to assess the effect of aboveground intra- and interspecific competition on tree growth. Forest Ecology and Management 310: 275-288. - doi: 10.1016/j. foreco.2013.08.014

Moorthy I, Miller JR, Berni JAJ, Zarco-Tejada PJ, $\mathrm{Hu} B$, Chen J (2011). Field characterization of olive (Olea europaea L.) tree crown architecture using terrestrial laser scanning data. Agricultural and Forest Meteorology 151: 204-214. - doi: 10.1016/j.agrformet.2010.10.005

Morhart CD, Sheppard JP, Spiecker H (2013). Above ground leafless woody biomass and nutrient content within different compartments of a $P$. maximowicii $\times P$. trichocarpa poplar clone. Forests 4: 471-487. - doi: 10.3390/f40 20471
Morhart CD, Sheppard JP, Schuler JK, Spiecker H (2016). Above-ground woody biomass allocation and within tree carbon and nutrient distribution of wild cherry (Prunus avium L.) - a case study. Forest Ecosystems 3: 1-15. - doi: 10.1186/ s40663-016-0063-x

Newnham GJ, Armston JD, Calders K, Disney MI, Lovell JL, Schaaf CB, Strahler AH, Danson FM (2015). Terrestrial laser scanning for plot-scale forest measurement. Current Forestry Reports 1: 239-251. - doi: 10.1007/s40725-015-0025-5

Pfeifer N, Gorte B, Winterhalder D (2004). Automatic reconstruction of single trees from terrestrial laser scan data. In: Proceedings of the 2oth ISPRS Congress "Geo-Imagery Bridging Continents" (Altan MO ed). Istanbul (Turkey) 12-23 Jul 2004. IASPR, vol.XXXV, pp. 114-119. [online] URL: http://www.Ir.tudelft.nl/Publicati ons/015-2004/automatic_reconstruction. pdf

Pretzsch H (2002). Grundlagen der Waldwachstumsforschung [Principles of forest growth research]. Parey, Berlin, Germany, pp. 23.

Pryor SN (1988). The silviculture and yield of wild cherry. Forestry Commission bulletin, vol 75 . Her Majesty's Stationery Office, London, UK, pp. 23.

Raumonen P, Kaasalainen M, Akerblom M, Kaasalainen S, Kaartinen H, Vastaranta M, Holopainen M, Disney M, Lewis P (2013). Fast automatic precision tree models from terrestrial laser scanner data. Remote Sensing 5: 491-520. - doi: $10.3390 /$ rs5020491

Roberts JW, Tesfamichael S, Gebreslasie M, Van Aardt J, Ahmed FB (2007). Forest structural assessment using remote sensing technologies: an overview of the current state of the art. Southern Hemisphere Forestry Journal 69: 183203. - doi: 10.2989/SHFJ.2007.69.3.8.358

Rusu RB, Cousins S (2011). 3D is here: Point Cloud Library (PCL). In: International Conference on Robotics and Automation (ICRA). Shanghai (China) 9-13 May 2011. IEEE Xplore Digital Library, pp. 1-4. [online] URL: http://ieeexplore. ieee.org/document/5980567/

Schuler J (2011). Astenwicklung und Astreinigung in Abhängigkeit vom Dickenwachstum bei Buche (Fagus sylvatica L.) und Eiche (Quercus petraea (Matt.) Liebl.; Quercus robur L.) [Branch development and natural pruning processes related to diameter growth of beech (Fagus sylvatica L.) and oak (Quercus petraea (Matt.) Liebl.; Quercus robur L.)]. Doctoral Dissertation, Institut für Waldwachstum, AlbertLudwigs-Universität Freiburg i. Br., Freiburg, Germany, pp. 285. [in German] [online] URL: https://freidok.uni-freiburg.de/data/8396

Sheppard JP, Urmes M, Morhart CD, Spiecker H (2016). Factors affecting branch wound occlusion and associated decay following pruning - a case study with wild cherry (Prunus avium L.). Annals of Silvicultural Research 40 (2): 16-22. Spiecker M (1994). Wachstum und Erziehung wertvoller Waldkirschen [Growth and tending of valuable wild cherries]. Mitteilungen der Forstlichen Versuchs- und Forschungsanstalt Baden-Württemberg Band 181, pp. 92. [in German]

Springmann S, Rogers R, Spiecker H (2011). Impact of artificial pruning on growth and secondary shoot development of wild cherry (Prunus avium L.). Forest Ecology and Manage- 
ment 261: 764-769. - doi: 10.1016/j.foreco.2010. 12.007

Srinivasan S, Popescu SC, Eriksson M, Sheridan RD, Ku N (2014). Multi-temporal terrestrial laser scanning for modeling tree biomass change. Forest Ecology and Management 318: 304-317. doi: 10.1016/j.foreco.2014.01.038

Thies M, Pfeifer N, Winterhalder D, Gorte B (2004). Three-dimensional reconstruction of stems for assessment of taper, sweep and lean based on laser scanning of standing trees. Scandinavian Journal of Forest Research: 571581. - doi: 10.1080/02827580410019562 Thies M, Hein S, Spiecker H (2009). Results of a questionnaire on management of valuable broadleaved forests in Europe. In: "Valuable broadleaved forests in Europe" (Spiecker $\mathrm{H}$, Hein S, Makkonen-Spiecker K, Thies M eds). Brill, Leiden, Netherlands and Boston, MS, USA, pp. 27-42.

Van Laar A, Akça A (1997). Forest mensuration ( $1^{\text {st }}$ edn). Cuvillier, Göttingen, Germany, pp. 418.

Van Leeuwen M, Nieuwenhuis M (2010). Retrieval of forest structural parameters using LiDAR remote sensing. European Journal of Forest Research 129: 749-770. - doi: 10.1007/s10 342-010-0381-4

Van Leeuwen M, Hilker T, Coops NC, Frazer G, Wulder MA, Newnham GJ, Culvenor DS (2011). Assessment of standing wood and fiber quality using ground and airborne laser scanning: A review. Forest Ecology and Management 261: 1467-1478. - doi: 10.1016/j.foreco.2011.01.032

Wassenberg $M$, Chiu $H$, Guo W, Spiecker $H$ (2015). Analysis of wood density profiles of tree stems: incorporating vertical variations to optimize wood sampling strategies for density and biomass estimations. Trees 29: 551-561. - doi: 10.1007/s00468-014-1134-7

Zanne AE, Lopez-Gonzalez G, Coomes DA, Ilic J, Jansen S, Lewis SL, Miller RB, Swenson NG, Wiemann MC, Chave J (2009). Data from: "Towards a worldwide wood economics spectrum". Dryad Digital Repository, Website. - doi: $10.5061 /$ dryad.234 